\title{
CDC73 gene mutations in sporadic ossifying fibroma of the jaws
}

Yan Chen ${ }^{1+}$, Da-Yan Hu ${ }^{2+}$, Ting-Ting Wang ${ }^{3}$, Ran Zhang ${ }^{1}$, Qing Dong ${ }^{2}$, Zhi-Xiu Xu' ${ }^{1}$ Lin Wang ${ }^{2 *}$ and Tie-Jun Li ${ }^{{ }^{*}}$

\begin{abstract}
Background: The tumor suppressor gene CDC73 was found to be associated with hyperparathyroidism-jaw tumor syndrome (HPT-JT), which is characterized by parathyroid adenoma or carcinoma, ossifying fibroma (OF) of the jaws, and renal and uterine lesions. Mutations in CDC73 have also been frequently detected in sporadic parathyroid carcinomas and renal tumors. However, the prevalence and range of CDC73 mutations in sporadic OFs have not been established.

Methods: We directly sequenced coding and flanking splice junctional regions of CDC73 in 40 cases of sporadic OF of the jaws. We also used immunohistochemistry to detect parafibromin, the protein product of $C D C 73$, in those cases.

Results: Two novel CDC73 mutations were identified in 2 of the 40 cases (5\%). Both were somatic mutations located in exon 1 of the coding region. Strong parafibromin expression was detected in all 40 cases, irrespective of the presence of CDC73 mutations.

Conclusions: Mutations inCDC73 were rare in sporadic OF of the jaws, but may affect the pathogenesis of a small subset of tumors of this type.
\end{abstract}

Keywords: CDC73, Ossifying fibroma, Sporadic

\section{Background}

According to the World Health Organization, it is proposed that benign fibro-osseous lesions be divided into 3 categories, including fibrous dysplasia, ossifying fibroma, and osseous dysplasia [1,2]. The most common forms of BFOL are ossifying fibroma (OF) and fibrous dysplasia (FD) and they manifest different clinical courses and should be treated differently [3].

Ossifying fibroma is a benign tumor thought to arise from the periodontal ligament, which potential of continuous growth if not treated [4, 5]. It is a slowgrowing, generally lack of symptoms, but can cause serious cosmetic and functional problems. [6] OF can occur in almost any bone in the craniofacial region,

\footnotetext{
* Correspondence: litiejun22@vip.sina.com; wang160@163.com

${ }^{\dagger}$ Equal contributors

'Department of Oral Pathology, Peking University School and Hospital of Stomatology, 22 South Zhongguancun Avenue, Haidian District, Beijing 100081, People's Republic of China

${ }^{2}$ Department of Oral Medicine, North China University of Science and Technology, School and Hospital of Stomatology, 82 South Construction Road, Lubei District, Tangshan 063000, People's Republic of China Full list of author information is available at the end of the article
}

predominantly in the premolar-molar region of the mandible, with adult women more frequently affected [7]. Radio-graphically, OF usually presents a wellcircumscribed radiolucency with varying degrees of calcification that rarely erodes or displaces teeth [4]. Ossifying fibromas are typically encountered as solitary lesions, multiple and/or familial lesions rarely present in clinic [8]. In some instances, OF can be destructive and risk for recurrence, as a result of which completely surgical enucleating is needed [9].

FDs are genetic and non-inheritable, caused by missense mutations that occur post-zygotically in the gene, GNAS, which is located on chromosome 20q13 and codes for the a-subunit of the stimulatory G-protein, Gs [10]. The mutations generate a somatic mosaic and the resulting proteins display reduced GTPase activity and, consequently, increased activation of adenylyl cyclase. Therefore, mutated cells constitutively generate high levels of cAMP and have a high rate of proliferation [11]. The differential diagnostic value of GNAS in FD is well recognized. In previous studies, our research group 
demonstrated that, in a total of 307 cases of FD and 23 cases of OF, the mutation rate of GNAS in patients with FD was approximately $86 \%$ (264/307), while GNAS mutations were not found in patients with OF. [12] Little is known about the etiology of OF.

Hyperparathyroidism-jaw tumor (HPT-JT) syndrome is an autosomal dominant, multiple neoplasia syndrome which is characterized by parathyroid adenoma or carcinoma, ossifying fibroma of the jaws, renal and uterine lesions [13, 14]. Between 30 and $40 \%$ of individuals with HPT-JT also develop OFs, which are distinct from the "brown" tumors associated with severe hyperparathyroidism.. The HPT-JT locus was mapped to chromosome 1q24-q32; the putative gene, designated first as hyperparathyroidism type 2 (HRPT2) and then as CDC73, encodes a 531 amino acid protein called parafibromin. [15] Parafibromin is ubiquitously expressed and is evolutionarily conserved. It is the human homologue of yeast Cdc73, which is a component of the yeast RNA polymerase II/Paf1 complex that is important for histone modification and post-transcriptional events $[16,17]$. Mutations in $C D C 73$ can be detected in approximately $58 \%$ of probands with clinical features of HPT-JT syndrome [15]. In one series, which included four cases with OFs, mutations in $C D C 73$ were found in two of the cases [18].

Collectively, these data suggested that $C D C 73$ may be a key factor in the etiology of HPT-JT syndrome and its related tumors, including OFs. The prevalence and range of $C D C 73$ mutations in sporadic OFs remain to be determined, in view of the limited number of cases examined to date. The goal of the present study was to identify $C D C 73$ mutations in a group of Chinese patients presenting with sporadic OFs and to examine the possible role of $C D C 73$ in the pathogenesis and diagnosis of OFs.

\section{Methods}

\section{Subjects and samples}

The fresh tumor specimens and peripheral blood samples of 40 sporadic OFs were obtained from the Department of Oral Pathology, Peking University Hospital and School of Stomatology, during 2003-2015. The diagnosis was made according to the WHO classification of odontogenic tumors [2]. Samples were only collected if the patient's family history was negative and PTH serum level was normal, to exclude cases of HPT-JT related OF. Detailed information regarding these cases is provided in Table 1.

\section{DNA Extraction and Polymerase Chain Reaction (PCR)}

Genomic DNA was extracted from frozen samples $(25 \mathrm{mg}$ ) of neoplastic tissue and peripheral blood by using a DNeasy Tissue Kit (Qiagen Sciences, Maryland,
USA). The 17 coding exons of $C D C 73$ were amplified as 15 different fragments with primers derived from the flanking intronic or $3^{\prime} / 5^{\prime}$ UTR regions, to allow the detection of mutations that occurred in coding regions or that affected splicing, as previously described [19]. The condition of PCR was used as follows: initial denaturation at $95^{\circ} \mathrm{C}$ for $5 \mathrm{~min} ; 35$ cycles of denaturation at $95^{\circ}$ $\mathrm{C}$ for $30 \mathrm{~s}$, annealing at $58-62{ }^{\circ} \mathrm{C}$ for $30 \mathrm{~s}$, elongation at $72{ }^{\circ} \mathrm{C}$ for $30 \mathrm{~s}$; and a final extension at $72{ }^{\circ} \mathrm{C}$ for $7 \mathrm{~min}$.

\section{Direct sequencing}

The amplified PCR products were gel-purified and directly sequenced. When nucleotides insertion or deletion was detected, clone sequencing by the plasmid vector was used for confirmation. The method of clone sequencing were carried out by previously described [20]. All detected mutations were confirmed by reverse sequencing and at least two independent experiments.

\section{Immunohistochemistry}

Parafibromin expression was evaluated in formalin-fixed and paraffin-embedded tissues by immunohistochemical staining as previously described [21], using a mouse monoclonal anti-parafibromin antibody (SC-33638, Santa Cruz Biotechnology Inc., Santa, Cruz, CA, USA) that recognizes amino acids $87-100$.

\section{Results \\ Clinicopathological features}

The clinical characteristics of the 40 cases enrolled in this study are summarized in Table 1 . The patient age at first presentation ranged from 1 to 47 years (median age: 19.5 years). The male to female ratio was 19:21. Seventeen $(44.7 \%, 17 / 38)$ tumors occurred in the maxilla, while $21(55.3 \%, 21 / 38)$ occurred in the mandible. Two cases, which have been reported previously [8], showed multiple lesions affecting both the maxilla and the mandible. Bone or facial swelling $(90 \%, 36 / 40)$ was the most common clinical presentation, and other presentations included pain $(10 \%, 4 / 40)$, bite pain $(2.5 \%, 1 / 40)$, nasal obstruction $(5 \%, 2 / 40)$, sense of numbness $(7.5 \%, 3 / 40)$, sense of discomfort $(5 \%, 2 / 40)$, looseness of teeth $(2.5 \%, 1 / 40)$, tinnitus $(2.5 \%, 1 / 40)$, and surface fester $(2.5 \%, 1 / 40)$. In 38 of 40 patients with available radiographs, radiographic features included radiolucent (eight cases, $21 \%$ ), mixed (25 cases, $66 \%$;), and radioopaque lesions (5 cases, $13 \%$ ). Lesions of 29 cases were well-defined, and those of 9 cases were ill-defined.

\section{CDC73 mutations}

Results from the mutational analysis of $C D C 73$ in 40 cases of OF are summarized in Table 1 . Two novel CDC73 mutations were identified in two cases. Both mutations were 
Table 1 Clinical data and CDC73 mutation of 40 patients with sporadic ossifying fibromas

\begin{tabular}{|c|c|c|c|c|c|c|c|}
\hline Patient & Age (y) & Gender & Location & Symptoms and signs & Radiographic fi & ings & CDC73 mutation \\
\hline 1 & 10 & female & right maxilla & $\begin{array}{l}\text { right facial swelling } \\
\text { bite pain }\end{array}$ & Mixed lesion & well demarcated & c.13-16delCTTA \\
\hline 2 & 18 & female & left mandible & $\begin{array}{l}\text { left posterior teeth } \\
\text { discomfort }\end{array}$ & Mixed lesion & well demarcated & c.8-10delACGinsC \\
\hline 3 & 23 & female & left mandible & bone swelling & Mixed lesion & ill demarcated & No mutation \\
\hline 4 & 18 & female & right mandible & $\begin{array}{l}\text { right facial swelling } \\
\text { occasional discomfort }\end{array}$ & Mixed lesion & well demarcated & No mutation \\
\hline 5 & 20 & female & left maxilla & $\begin{array}{l}\text { left facial swelling } \\
\text { surface fester }\end{array}$ & Mixed lesion & well demarcated & No mutation \\
\hline 6 & 46 & female & left mandible & $\begin{array}{l}\text { bone swelling } \\
\text { numbness of lower lip }\end{array}$ & unavailable & unavailable & No mutation \\
\hline 7 & 39 & female & left mandible & bone swelling & Radiolucent & well demarcated & No mutation \\
\hline 8 & 1 & male & right mandible & right facial swelling & unavailable & unavailable & No mutation \\
\hline 9 & 14 & male & left mandible & bone swelling & Radio-opaque & well demarcated & No mutation \\
\hline 10 & 34 & male & left mandible & left facial swelling & Radio-opaque & well demarcated & No mutation \\
\hline 11 & 10 & male & left maxilla & $\begin{array}{l}\text { right facial swelling } \\
\text { tinnitus }\end{array}$ & Radiolucent & well demarcated & No mutation \\
\hline 12 & 43 & female & $\begin{array}{l}\text { anterior maxillary } \\
\text { region }\end{array}$ & bone swelling & Radio-opaque & well demarcated & No mutation \\
\hline 13 & 15 & male & left mandible & bone swelling & Mixed lesion & well demarcated & No mutation \\
\hline 14 & 22 & female & left maxilla & bone swelling & Radio-opaque & well demarcated & No mutation \\
\hline 15 & 31 & female & right mandible & $\begin{array}{l}\text { buccal and lingual bone } \\
\text { expansion } \\
\text { mildly pain }\end{array}$ & Mixed lesion & well demarcated & No mutation \\
\hline 16 & 32 & female & left mandible & $\begin{array}{l}\text { buccal and lingual bone } \\
\text { expansion }\end{array}$ & Mixed lesion & well demarcated & No mutation \\
\hline 17 & 37 & male & right maxilla & $\begin{array}{l}\text { right facial swelling } \\
\text { pain and fever }\end{array}$ & Mixed lesion & well demarcated & No mutation \\
\hline 18 & 43 & female & right maxilla & buccal bone expansion & Mixed lesion & well demarcated & No mutation \\
\hline 19 & 47 & male & right maxilla & $\begin{array}{l}\text { bone swelling } \\
\text { nasal obstruction }\end{array}$ & Mixed lesion & ill demarcated & No mutation \\
\hline 20 & 6 & male & right maxilla & bone swelling & Mixed lesion & well demarcated & No mutation \\
\hline 21 & 9 & male & right mandible & right facial swelling & Radiolucent & well demarcated & No mutation \\
\hline 22 & 24 & female & $\begin{array}{l}\text { anterior mandibular } \\
\text { region }\end{array}$ & pain & Mixed lesion & well demarcated & No mutation \\
\hline 23 & 26 & male & left maxilla & buccal bone expansion & Mixed lesion & well demarcated & No mutation \\
\hline 24 & 10 & male & left maxilla & left facial swelling & Mixed lesion & well demarcated & No mutation \\
\hline 25 & 11 & male & right maxilla & nasal obstruction & Mixed lesion & well demarcated & No mutation \\
\hline 26 & 5 & male & left maxilla & bone swelling & Mixed lesion & well demarcated & No mutation \\
\hline 27 & 44 & female & right maxilla & sense of numbness & Mixed lesion & ill demarcated & No mutation \\
\hline 28 & 31 & female & left mandible & $\begin{array}{l}\text { bone swelling } \\
\text { looseness of teeth }\end{array}$ & Radiolucent & well demarcated & No mutation \\
\hline 29 & 17 & male & right maxilla & bone swelling & Mixed lesion & ill demarcated & No mutation \\
\hline 30 & 20 & female & right mandible & $\begin{array}{l}\text { bone swelling } \\
\text { occasional pain }\end{array}$ & Mixed lesion & well demarcated & No mutation \\
\hline 31 & 6 & male & left mandible & bone swelling & Radiolucent & ill demarcated & No mutation \\
\hline 32 & 11 & female & right mandible & right facial swelling & Mixed lesion & well demarcated & No mutation \\
\hline 33 & 14 & male & $\begin{array}{l}\text { anterior mandibular } \\
\text { region }\end{array}$ & labial bone expansion & Radiolucent & ill demarcated & No mutation \\
\hline
\end{tabular}


Table 1 Clinical data and CDC73 mutation of 40 patients with sporadic ossifying fibromas (Continued)

\begin{tabular}{|c|c|c|c|c|c|c|c|}
\hline 34 & 20 & female & left maxilla & bone swelling & Radio-opaque & well demarcated & No mutation \\
\hline 35 & 21 & female & right mandible & bone swelling & Radiolucent & ill demarcated & No mutation \\
\hline 36 & 7 & male & right mandible & $\begin{array}{l}\text { bone swelling } \\
\text { numbness of lower lip }\end{array}$ & Mixed lesion & ill demarcated & No mutation \\
\hline 37 & 8 & male & left maxilla & left facial swelling & Mixed lesion & ill demarcated & No mutation \\
\hline 38 & 27 & female & left mandible & bone swelling & Mixed lesion & well demarcated & No mutation \\
\hline \multirow[t]{2}{*}{39} & 19 & female & Les.1:right maxilla & hard bone swelling & Radiolucent & well demarcated & No mutation \\
\hline & & & Les.2:bilateral mandible & & & & \\
\hline \multirow[t]{4}{*}{40} & 6 & male & Les.1: right maxilla & bone swelling & Mixed lesion & well demarcated & No mutation \\
\hline & & & Les.2: left maxilla & & & & \\
\hline & & & Les.3: right mandible & & & & \\
\hline & & & Les.4: left mandible & & & & \\
\hline
\end{tabular}

somatic and located in exon 1 . The mutation in case 1 was a frameshift mutation (c.13_16delCTTA), which leads to a premature stop codon at position 15 . The frameshift mutation also causes the substitution of the fifth amino acid, leucine, which was the first affected amino acid, with an alanine (p.Leu5Alafs*15). The novel mutation found in case 2, c.8_10delACGinsCT, was a frameshift mutation that leads to a premature stop codon at position 18. This mutation causes the substitution of the third amino acid, aspartic acid, with an alanine (p.Asp3Alafs*18) (Fig. 1).
Immunohistochemical detection of parafibromin expression

Using immunohistochemical analysis, we found that all cases of sporadic OF showed strong parafibromin expression in the nucleus, and that some showed parafibromin expression in the cytoplasm of the spindleshaped lesion cells, including those cells that were carriers of a CDC73 mutation (Fig. 2).

\section{Discussion}

Parafibromin, the product of $C D C 73$, is believed to be important for embryonic development and tumorigenesis

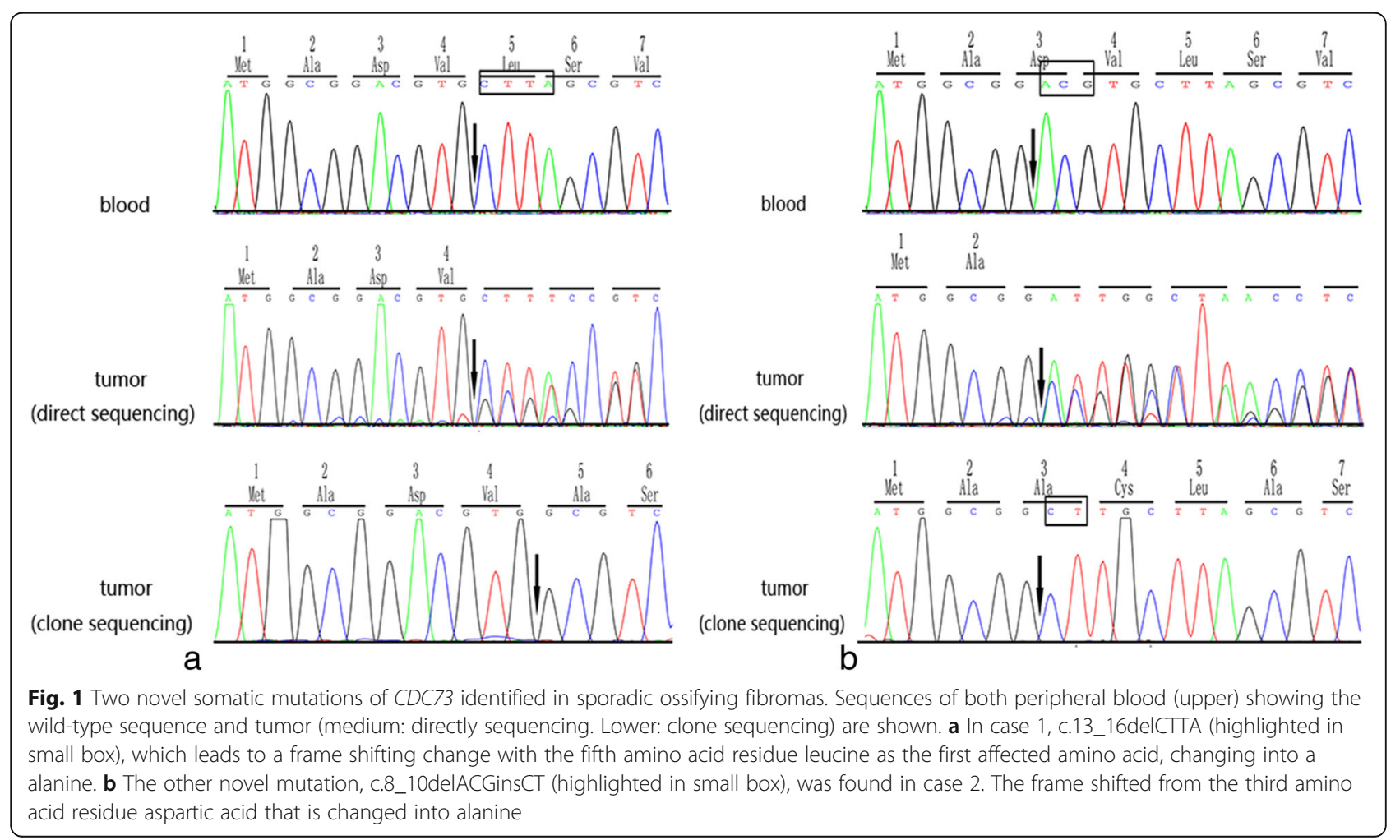



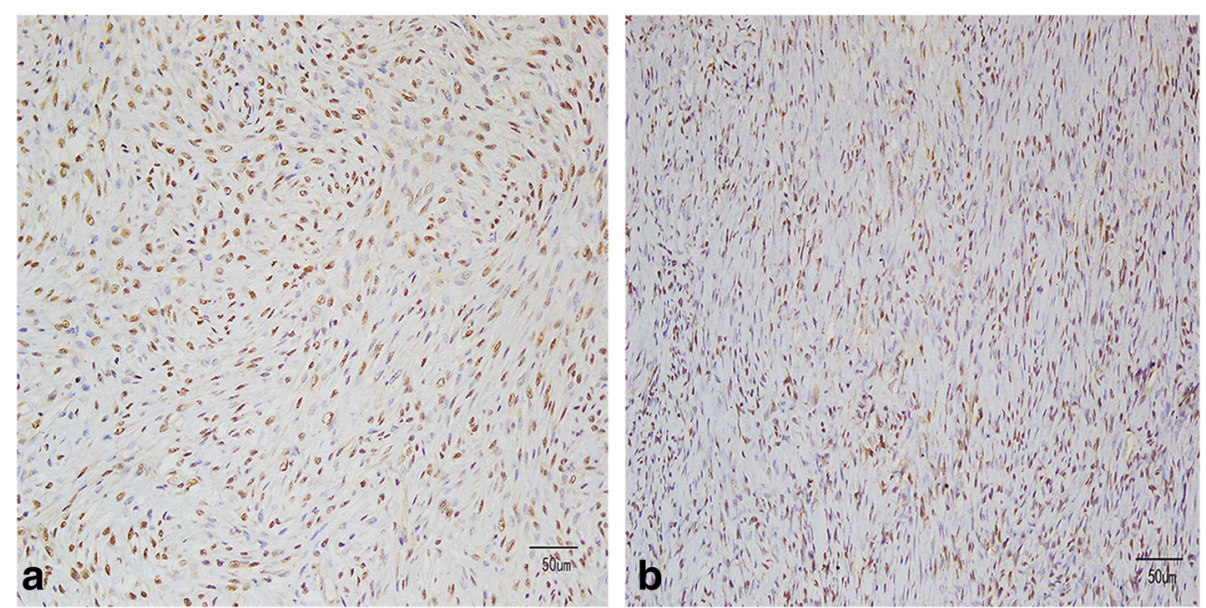

Fig. 2 Parafibromin staining by immunohistochemistry. All tumors, without (a) or with (b) CDC73 mutation (*200), showed strong nuclear and cytoplasmic staining in both fibroblasts and osteoblasts within the lesion

[15]. Homozygous $C D C 73$ knockout mutations in mice led to in utero death by stage E6.5. Conditional knockout of both $C D C 73$ alleles in E8.5 or older mice resulted in the retardation of embryonic growth and increased apoptosis, whereas in adult mice it resulted in cachexia and death within 20 days [22]. Parafibromin is a ubiquitously expressed nuclear protein [21]. In humans, parafibromin interacts with RNA polymerase II via the human PAF1 complex, which also includes human Paf1, CTR9, and Leo1. This complex regulates a number of key transcriptional events, including transcription initiation, transcript elongation, and post-transcriptional events, including mRNA maturation and maintenance of poly (A) tail length $[16,17]$.

Mutations in $C D C 73$ have been frequently detected in patients with HPT-JT and also occur in $20-29 \%$ of individuals with apparently sporadic parathyroid carcinoma [23]. However, the frequency of $C D C 73$ mutations in sporadic parathyroid adenomas is low, at $0-4 \%$, indicating that $C D C 73$ mutations likely confer an aggressive growth potential and may result in malignant transformation of parathyroid cells [24]. CDC73 mutations have been detected in between 0 and $33 \%$ of individuals with familial isolated primary hyperparathyroidism [23]. Somatic $C D C 73$ mutations have also been found in sporadic renal tumors [25].

The frequency of $C D C 73$ mutations in individuals with sporadic OF of the jaws has not been extensively studied. In the present study, two somatic mutations were identified in 40 cases of OF (5\%). This result suggested a possible pathogenetic role for $C D C 73$ in some cases of sporadic OFs. Previously, a few cases of sporadic OF was found to harbor a mutation in $C D C 73[18,26]$. Further studies are needed to clarified the exact frequency of CDC73 mutation in sporadic OF due to limitation of sample size.
The $C D C 73$ mutations identified in this study included two novel somatic mutations (c.13_16delCTTA and c.8_10delACGinsCT), which caused frameshifts and premature truncations of the protein. This finding is consistent with previous studies showing that over $75 \%$ of the reported $C D C 73$ mutations are frameshift or nonsense mutations that are predicted to result in either the truncation of the parafibromin protein or in loss of the translated protein through nonsense-mediated mRNA decay.

Somatic mutations of $C D C 73$ were predominantly located in exons 1 and 2 (55 and $21 \%$, respectively), in contrast to germline mutations (22 and $16 \%$, respectively) mainly detected in HPT-JT, which were predominantly located in exon 7 (30\%). Only one somatic mutation has been detected in exon 7 to date [24]. The two mutations that we identified in OF both occurred in exon 1, and a previous study on OF [18] also identified a somatic mutation in exon 1 . The basis of the differences in the distribution of the germline and somatic $C D C 73$ mutations remains to be elucidated.

In vitro studies have shown that parafibromin acts as a tumor suppressor. Overexpression of parafibromin inhibits the proliferation of NIH3T3 and HEK293 cells, increases G1 arrest and apoptosis in HeLa cells, and downregulates expression of the cell cycle regulator, cyclin D1 [27-29]. Likewise, RNAi-mediated inhibition of parafibromin expression in HeLa cells resulted in increased S-phase entry with reduction in basal apoptosis and increase in expression of the proto-oncogene, c-myc [30, 31].

According to Knudson's two-hit model for tumor suppressor genes [32] two mutations, one occurring in each of the two alleles of a gene, or one mutation in one allele of a tumor suppressor gene accompanied by the allelic 
loss of the remaining wild-type allele, are required to trigger neoplasm formation. Biallelic inactivation in CDC73 has been detected in tumors in HPT-JT kindred and in sporadic parathyroid carcinomas and renal carcinomas [15]. Since parafibromin is ubiquitously expressed, biallelic inactivation of $C D C 73$ can be detected immunohistochemically by the diffuse loss of nuclear expression. This is a common feature in parathyroid carcinoma [33, 34].

However, the two-hit model may not apply to sporadic OF. First, only one mutation was detected in each case, even in the case with two somatic mutations reported by Pimenta [18]. Second, normal parafibromin expression was detected by immunohistochemistry. The effect of mutated $C D C 73$ on sporadic OFs needs to be studied further.

\section{Conclusions}

Although $C D C 73$ mutations are rare in sporadic OFs of the jaws, $C D C 73$ may play a role in the pathogenesis of a small subset of tumors.

\section{Abbreviations}

BFOL: Benign fibro-osseous lesion; FD: Fibrous dysplasia; HPTJT: Hyperparathyroidism-jaw tumor syndrome; OF: Ossifying fibroma; PTH: Parathyroid hormone

\section{Acknowledgements}

The authors gratefully acknowledge the patients for their cooperation.

\section{Funding}

This work was supported by Research Grants from the National Natural Science Foundation of China (81141092 and 81302349).

\section{Availability of data and materials}

The novel genetic data reported in this study has been submitted to ClinVar repository [http://www.ncbi.nlm.nih.gov/clinvar/] with the following accession number: SCV000292053, SCV000292054.

\section{Authors' contributions}

$\mathrm{CY}$ and DYH carried out the histopathological evaluation and the molecular genetic studies, participated in the sequence alignment, and drafted the manuscript. TTW, RZ, QD, and ZXX provided research data and assist in drafting the manuscript. LW and TJL conceived of the study, and participated in its design and coordination and helped to draft the manuscript. All authors read and approved the final manuscript.

\section{Competing interests}

The authors declare that they have no competing interests.

\section{Consent for publication}

Not applicable.

\section{Ethics approval and consent to participate}

The study protocol was approved by the Ethical Committee for Human Experiments at Peking University School of Stomatology (No:2013-NNS-08). Informed consent, obtained at the time of clinical intervention for the future use of material for research purposes, was obtained from all patients or the parents/guardians of patients who were children.

\section{Author details}

'Department of Oral Pathology, Peking University School and Hospital of Stomatology, 22 South Zhongguancun Avenue, Haidian District, Beijing 100081, People's Republic of China. ${ }^{2}$ Department of Oral Medicine, North China University of Science and Technology, School and Hospital of
Stomatology, 82 South Construction Road, Lubei District, Tangshan 063000, People's Republic of China. ${ }^{3}$ Department of Stomatology, The First Affiliated Hospital of Bengbu Medical College, 287 Changhuai Road, Bengbu 233004, People's Republic of China.

Received: 9 December 2015

Published online: 22 September 2016

\section{References}

1. Akcam T, Altug HA, Karakoc O, Sencimen M, Ozkan A, Bayar GR, et al. Synchronous ossifying fibromas of the jaws: a review. Oral Surg Oral Med Oral Pathol Oral Radiol. 2012;114(Supp 1):120-5.

2. Slootweg PJ, El Mofty SK. Ossifying fibroma. In: Barnes L, Eveson J, Reichart P, Sidransky D, editors. World Health Organization classification of tumors: pathology and genetics of head and neck tumors. Lyon: IARC; 2005. p. 309-10.

3. Toyosawa S, Yuki M, Kishino M, Ogawa Y, Ueda T, Murakami S, et al. Ossifying fibroma vs fibrous dysplasia of the jaw: molecular and immunological characterization. Mod Pathol. 2007;20(3):389-96.

4. Speight PM, Carlos R. Maxillofacial fibro-osseous lesions. Curr Diagn Pathol. 2006;12(1):1-10

5. Hall G. Fibro-osseous lesions of the head and neck. Diagn Histopathol. 2012;18(4):149-58

6. Chambers MS, Rassekn $\mathrm{CH}$, Toth BB, Lemon JC, Hoffman RD, A maxillary fibro-osseous lesion: differential diagnosis and case report. Tex Dent J. 2002; 119(1):12-9.

7. Waldron CA. Fibro-osseous lesions of the jaws. J Oral Maxillofac Surg. 1993; 51(8):828-35.

8. Wang TT, Zhang R, Wang L, Chen Y, Dong Q, Li TJ. Two cases of multiple ossifying fibromas in the jaws. Diagn Pathol. 2014;9:75. doi:10.1186/17461596-9-75.

9. Alawi F. Benign fibro-osseous diseases of the maxillofacial bones. A review and differential diagnosis. Am J Clin Pathol. 2002;118 Suppl:S50-70.

10. Weinstein LS, Shenker A, Gejman PV, Merino MJ, Friedman E, Spiegel AM. Activating mutations of the stimulatory $\mathrm{G}$ protein in the McCune-Albright syndrome. N Engl J Med. 1991;325(24):1688-95.

11. Happle R. The McCune-Albright syndrome: a lethal gene surviving by mosaicism. Clin Genet. 1986;29(4):321-4.

12. Shi RR, Li XF, Zhang R, Chen Y, Li TJ. GNAS mutational analysis in differentiating fibrous dysplasia and ossifying fibroma of the jaw. Mod Pathol. 2013;26(8):1023-31.

13. Chen JD, Morrison C, Zhang C, Kahnoski K, Carpten JD, Teh BT. Hyperparathyroidism-jaw tumour syndrome. J Intern Med. 2003;253(6):634-42

14. Aldred MJ, Talacko AA, Savarirayan R, Murdolo V, Mills AE, Radden BG, et al. Dental findings in a family with hyperparathyroidism-jaw tumor syndrome and a novel HRPT2 gene mutation. Oral Surg Oral Med Oral Pathol Oral Radiol Endod. 2006;101(2):212-8.

15. Carpten JD, Robbins CM, Villablanca A, Forsberg L, Presciuttini S, Bailey-Wilson J, et al. HRPT2, encoding parafibromin, is mutated in hyperparathyroidism-jaw tumor syndrome. Nat Genet. 2002;32(4):676-80.

16. Yart A, Gstaiger M, Wirbelauer C, Pecnik M, Anastasiou D, Hess D, et al. The HRPT2 tumor suppressor gene product parafibromin associates with human PAF1 and RNA polymerase II. Mol Cell Biol. 2005:25(12):5052-60.

17. Rozenblatt-Rosen O, Hughes CM, Nannepaga SJ, Shanmugam KS, Copeland TD, Guszczynski T, et al. The parafibromin tumor suppressor protein is part of a human Paf1 complex. Mol Cell Biol. 2005;25(2):612-20.

18. Pimenta FJ, Gontijo Silveira LF, Tavares GC, Silva AC, Perdigao PF, Castro WH, et al. HRPT2 gene alterations in ossifying fibroma of the jaws. Oral Oncol. 2006;42(7):735-9.

19. Villablanca A, Calender A, Forsberg L, Hoog A, Cheng JD, Petillo D, et al, Germline and de novo mutations in the HRPT2 tumour suppressor gene in familial isolated hyperparathyroidism (FIHP). J Med Genet. 2004;41(3):e32.

20. Gu XM, Zhao HS, Sun LS, Li TJ. PTCH mutations in sporadic and Gorlinsyndrome-related odontogenic keratocysts. J Dent Res. 2006;85(9):859-63.

21. Porzionato A, Macchi V, Barzon L, Masi G, lacobone M, Parenti A, et al. Immunohistochemical assessment of parafibromin in mouse and human tissues. J Anat. 2006;209(6):817-27.

22. Wang P, Bowl MR, Bender S, Peng J, Farber L, Chen J, et al. Parafibromin, a component of the human PAF complex, regulates growth factors and is 
required for embryonic development and survival in adult mice. Mol Cell Biol. 2008;28(9):2930-40.

23. Jackson MA, Rich TA, Hu Ml, Perrier ND, Waguespack SG. CDC73-Related Disorders. In: GeneReviews ${ }^{\oplus}$ [nternet]. 1993-2015. http://www.ncbi.nlm.nih. gov/books/NBK3789/. Accessed 31 Dec 2008.

24. Newey PJ, Bowl MR, Cranston T, Thakker RV. Cell division cycle protein 73 homolog (CDC73) mutations in the hyperparathyroidism-jaw tumor syndrome (HPT-JT) and parathyroid tumors. Hum Mutat. 2010;31(3):295-307.

25. Zhao J, Yart A, Frigerio S, Perren A, Schraml P, Weisstanner C, et al. Sporadic human renal tumors display frequent allelic imbalances and novel mutations of the HRPT2 gene. Oncogene. 2007;26(23):3440-9.

26. de Mesquita Netto AC, Gomez RS, Diniz MG, Fonseca-Silva T, Campos K, De Marco $L$, et al. Assessing the contribution of HRPT2 to the pathogenesis of jaw fibrous dysplasia, ossifying fibroma, and osteosarcoma. Oral Surg Oral Med Oral Pathol Oral Radiol. 2013;115(3):359-67.

27. Iwata T, Mizusawa N, Taketani Y, Itakura M, Yoshimoto K. Parafibromin tumor suppressor enhances cell growth in the cells expressing SV40 large T antigen. Oncogene. 2007;26(42):6176-83.

28. Zhang C, Kong D, Tan MH, Pappas Jr DL, Wang PF, Chen J, et al. Parafibromin inhibits cancer cell growth and causes G1 phase arrest. Biochem Biophys Res Commun. 2006;350(1):17-24.

29. Woodard GE, Lin L, Zhang JH, Agarwal SK, Marx SJ, Simonds WF. Parafibromin, product of the hyperparathyroidism-jaw tumor syndrome gene HRPT2, regulates cyclin D1/PRAD1 expression. Oncogene. 2005;24(7):1272-6.

30. Lin L, Zhang JH, Panicker LM, Simonds WF. The parafibromin tumor suppressor protein inhibits cell proliferation by repression of the c-myc proto-oncogene. Proc Natl Acad Sci U S A. 2008;105(45):17420-5.

31. Lin L, Czapiga M, Nini L, Zhang JH, Simonds WF. Nuclear localization of the parafibromin tumor suppressor protein implicated in the hyperparathyroidism-jaw tumor syndrome enhances its proapoptotic function. Mol Cancer Res. 2007:5(2):183-93.

32. Knudson Jr AG. Mutation and cancer: statistical study of retinoblastoma. Proc Natl Acad Sci U S A. 1971:68(4):820-3.

33. Tan MH, Morrison C, Wang P, Yang X, Haven CJ, Zhang C, et al. Loss of parafibromin immunoreactivity is a distinguishing feature of parathyroid carcinoma. Clin Cancer Res. 2004;10(19):6629-37.

34. Juhlin CC, Villablanca A, Sandelin K, Haglund F, Nordenstrom J, Forsberg L, et al. Parafibromin immunoreactivity: its use as an additional diagnostic marker for parathyroid tumor classification. Endocr Relat Cancer. 2007;14(2):501-12.

\section{Submit your next manuscript to BioMed Central and we will help you at every step:}

- We accept pre-submission inquiries

- Our selector tool helps you to find the most relevant journal

- We provide round the clock customer support

- Convenient online submission

- Thorough peer review

- Inclusion in PubMed and all major indexing services

- Maximum visibility for your research

Submit your manuscript at www.biomedcentral.com/submit

) Biomed Central 